\title{
Comparative Study of Intraocular Pressure Measurements with Airpuff, iCare and Goldmann Applanation Tonometers
}

\author{
Umair Tariq Mirza ${ }^{1}$, M. Usman Sadiq ${ }^{2}$, M. Irfan Sadiq ${ }^{3}$, Ali Raza ${ }^{4}$, Waseem Ahmed Khan ${ }^{5}$ \\ ${ }^{1-4}$ Mohi-ud-Din Islamic Medical College, Mirpur Azad Kashmir \\ ${ }^{5}$ Mohtarma Benazir Bhutto Shaheed Medical College
}

\begin{abstract}
Purpose: To compare the difference in intraocular pressure (IOP) measurements by Airpuff, iCare and Goldmann Applanation Tonometers (GAT).

Study Design: Comparative analytical study.

Place and Duration of Study: Department of Ophthalmology, Mohi-ud-Din Teaching Hospital, Mirpur Azad Kashmir, from June 2020 to August 2020.

Methods: Twenty-five patients (50 eyes) were included in this study. IOP was measured in each eye firstly by Airpuff tonometery, then by iCare tonometery and lastly by Goldmann applanation tonometer. Three consecutive readings were taken in each eye. If there was a difference of $2 \mathrm{~mm} \mathrm{Hg}$ or more among the readings, measurement was repeated. Once we got three readings, their average was taken and analyzed. Comparison of IOP readings between these tonometers was done.

Results: Mean IOP was $15.84 \pm 2.736 \mathrm{~mm} \mathrm{Hg}$ with Airpuff Tonometer, $14.48 \pm 2.435 \mathrm{~mm} \mathrm{Hg}$ with iCare Tonopen and $14.74 \pm 2.489 \mathrm{~mm} \mathrm{Hg}$ with Goldman Applanation Tonometer. The difference between the mean Airpuff and Goldman Applanation Tonometer readings was $1.10 \mathrm{~mm} \mathrm{Hg}$ which was not statistically significant $(p$-value = 0.083). The difference between the mean Goldman Applanation Tonometer and iCare Tonopen readings was $0.26 \mathrm{~mm} \mathrm{Hg}$ which is also not statistically significant ( $p$-value $=0.867)$. But, the difference between the mean iCare Tonopen and Airpuff Tonometer readings was $-1.36 \mathrm{~mm} \mathrm{Hg}$ which was statistically significant $(p$-value = 0.02).

Conclusion: It is concluded that IOP readings taken by iCare Tonopen and Airpuff Tonometer are comparable to those taken by Goldman Applanation Tonometer and iCare Tonopen underestimates the IOP when compared with Airpuff Tonometer.
\end{abstract}

Key Words: Airpuff Tonometer, Glaucoma, Goldmann Applanation Tonometer, iCare Tonometer, Intraocular Pressure.

How to Cite this Article: Mirza UT, Sadiq MU, Sadiq MI, Raza A, Khan WA. Comparative Study of Intraocular Pressure Measurements with Airpuff, iCare and Goldmann Applanation Tonometers. Pak J Ophthalmol. 2021, 37 (1): 57-61.

Doi: https://doi.org/10.36351/pjo.v37i1.1139

Correspondence: Umair Tariq Mirza

Mohi-ud-Din Islamic Medical College

Mirpur Azad Kashmir

Email: utmirza@gmail.com

Received, September 21, 2020

Accepted, November 20, 2020

\section{INTRODUCTION}

Intraocular pressure (IOP) is the aqueous pressure determined by the equilibrium between the amount of aqueous humor produced, by the ciliary body, and drained through the trabecular meshwork. ${ }^{1}$ Tonometry is the method by which IOP is measured and its

Pak J Ophthalmol. 2021, Vol. 37 (1): 57-61 
accurate measurement is necessary in evaluation of patients at risk of glaucoma. ${ }^{2}$ An accurate IOP measurement is mandatory component of ophthalmological examination in clinical practice.

The range of IOP in the general population is about $11-21 \mathrm{~mm} \mathrm{Hg} .{ }^{3}$ In some cases, glaucomatous changes are noticed even with IOP values less than 21 $\mathrm{mm} \mathrm{Hg}$ i.e. Normal tension glaucoma (NTG). ${ }^{4}$ While in other cases with IOP more than $21 \mathrm{~mm} \mathrm{Hg}$, no glaucomatous changes are detected i.e. Ocular hypertension. ${ }^{5}$ There are some factors, which influence IOP value, one of most important such factor is central corneal thickness (CCT). ${ }^{6}$

Glaucoma can be classified in different ways. ${ }^{7}$ There are many methods to measure IOP. In Airpuff tonometery, the central corneal surface is flattened by a jet of air and time needed to do so is directly proportional to IOP. As it is done without topical anesthesia and there is no contact made with the eye, it is ideal for community screening. For more accurate readings, at least three readings are taken to get an average. ${ }^{8}$ iCare tonopen is based on rebound tonometry in which there is a thin wire with attached $1.8 \mathrm{~mm}$ plastic ball, when probe decelerates upon corneal contact, the magnitude of deceleration is directly proportional to IOP. ${ }^{9}$ No anesthesia is needed in this procedure as well, thus it is also helpful for community screening. While in Goldmann applanation tonometry (GAT), Imbert-Fick principle is applied according to which the pressure $(P)$ inside a dry thinwalled sphere is equal to the force $(F)$ needed to flatten its surface divided by the area $(A)$ which is flattened (i.e. $\mathrm{P}=\mathrm{F} / \mathrm{A})$. This requires topical anesthesia and there is corneal contact made. For this reason disinfection between patients is needed thus it is not suitable for mass screening. ${ }^{10}$ Disposable tonometer prisms and caps can also be used to address the need of repeated disinfection between patients.

The objective of this study was to compare the IOP measurements by Airpuff tonometer, iCare tonometer and Goldmann Applanation Tonometer (GAT) and to evaluate the accuracy and reliability of the three IOP measurement methods.

\section{METHODS}

This study was carried out at the Department of Ophthalmology, Mohi-ud-Din Teaching Hospital, Mirpur Azad Kashmir. Study period was from $1^{\text {st }}$ June 2020 to $31^{\text {st }}$ August 2020. Ethical approval was obtained from the Ethical Committee of the hospital. Informed written consent was obtained from all patients and detailed counseling was done about the procedure and results.

Twenty-five patients (50 eyes) were included in this study out of which 15 were males and 10 were females. Mean age of the participants was $30.36 \pm$ 5.376 years. The sample size was calculated using WHO sample size calculator on the basis of recent study. ${ }^{11}$ All patients were enrolled from ophthalmology out-patient department (OPD), Mohiud-Din teaching hospital, the affiliated hospital of Mohi-ud-Din Islamic Medical College, Mirpur Azad Kashmir. Any patient with central corneal opacity, corneal astigmatism, nystagmus, ocular surface disease i.e. dry eyes and conjunctivitis, ocular trauma was excluded from the study. History of contact lens use and refractive or intraocular surgery was also taken into consideration while setting exclusion criteria.

All enrolled patients were examined using Slit lamp. IOP measurements were taken using Airpuff iCare - GAT sequence while in the sitting position. All tonometers were properly calibrated before taking readings and there was a gap of 10 minutes maintained between each IOP measurement to reduce any after measurement fluctuation.

Tonometery was first performed in each patient with an Airpuff tonometer (Nidek RKT 7700, Nidek Corporation, Japan). Three consecutive readings were taken in each eye. If there was difference of $2 \mathrm{~mm} \mathrm{Hg}$ or more among the readings, measurement was repeated. Once we got three readings, their average was taken and analyzed. After ten minutes, IOP measurement was done with iCare pro (iCare Finland Oy, Helsinki, Finland). It has a single use/disposable probe, loaded into the instrument and was aligned 4-8 $\mathrm{mm}$ vertical to the central corneal surface. After six measurements were taken, the highest and lowest values were automatically discarded and the average IOP was calculated from the remaining four values by the built-in software. At the end Goldmann Applanation Tonometry was performed using GAT AT900, Haag Streit, Koniz, Switzerland installed on a slit-lamp biomicroscope. Three IOP readings were taken after instillation of a drop of $0.5 \%$ proparacaine hydrochloride (Alcaine) and $0.25 \%$ fluorescein in each eye. The final IOP was taken from the average value of these three measurements provided that there was no difference of $2 \mathrm{~mm} \mathrm{Hg}$ or more among these three values. All the measurements were taken by same 
ophthalmologist. Measurements by Airpuff Tonometery, iCare Tonometer, Goldmann Applanation Tonometer (GAT) were analyzed and compared with each other.

Data was entered and analyzed using Statistical Package for Social Sciences (SPSS) version 21. Mean and standard deviation were calculated for quantitative variable i.e. age. Qualitative variable like gender and eye involved were calculated by frequency and percentage. One way Anova and Tukey test were used to see the difference in intraocular pressure readings in all measurement methods. p-value of $<0.05$ was considered significant.

\section{RESULTS}

A total of 25 patients (50 eyes) were included in this study. Mean age of the patients was $30.36 \pm 5.376$ years $(21-39)$. There were 15 male patients and 10 female patients in the study (Figure 1). Out of 50 eyes, 25 were right eyes and 25 were left eyes. Overall the IOP measured by all instruments was $15.02 \pm 2.607$ $\mathrm{mm}$ of $\mathrm{Hg}$.

The IOP averages measured with all instruments are shown in Table 1. Mean IOP reading with Airpuff tonometer $15.84 \pm 2.736 \mathrm{~mm} \mathrm{Hg}$, with iCare Tonopen it $14.48 \pm 2.435 \mathrm{~mm} \mathrm{Hg}$ and with Goldman applanation tonometer was $14.74 \pm 2.489 \mathrm{~mm} \mathrm{Hg}$.

Table 1: Average IOP in each method with One Way Anova Test ( $p$ value $=0.021$ ).

\begin{tabular}{lccc}
\hline Method & n & IOP $(\mathbf{m m ~ o f ~ H g})$ & p Value \\
\hline Airpuff Tonometer & 50 & $15.84 \pm 2.736$ & \\
Goldmann Applanation & & $(10-21)$ & \\
Tonometer & 50 & $\begin{array}{c}14.74 \pm 2.489 \\
(10-20)\end{array}$ & \\
iCare Tonopen & & $14.48 \pm 2.435$ & 0.021 \\
& 50 & $(9-19)$ & \\
Total & & $15.02 \pm 2.607$ & \\
& 150 & $(9-21)$ & \\
\hline
\end{tabular}

Table 2: Differences in intraocular pressure (IOP) measurement methods using Tukey Test.

\begin{tabular}{lcc}
\hline Variable & $\begin{array}{c}\text { Mean Difference } \\
(\mathbf{m m} \text { of Hg) }\end{array}$ & p Value \\
\hline $\begin{array}{l}\text { Airpuff Tonometer - Goldman } \\
\text { Applanation Tonometer }\end{array}$ & 1.10 & 0.08 \\
$\begin{array}{l}\text { Goldman Applanation } \\
\text { Tonometer - iCare Tonopen }\end{array}$ & 0.26 & 0.87 \\
$\begin{array}{l}\text { iCare Tonopen - Airpuff } \\
\text { Tonometer }\end{array}$ & -1.36 & 0.02 \\
\hline
\end{tabular}

Overall, the difference was statistically significant with $\mathrm{p}$ value $=0.021$. Table 2 shows the differences between IOP measurement methods.

\section{DISCUSSION}

Goldmann applanation tonometry has been considered as a gold standard for IOP measurement for a long time. ${ }^{12,13}$ However, there are some instances in which IOP measurement by GAT is not possible or very difficult, for example in children and in bed ridden cases. ${ }^{14}$ Recent advancements have introduced many instruments and methods for measuring IOP. ${ }^{15}$ The reliability and accuracy of these instruments is comparable to GAT. ${ }^{16}$ Airpuff tonometer and a recently introduced iCare tonometer are some alternatives which can be used to measure IOP in challenging cases. ${ }^{17}$

In a recent study by Demirci et $\mathrm{al}^{16}$, measurements by rebound tonometer, non-contact airpuff tonometer and Goldmann applanation tonometer were compared in three groups of healthy subjects based upon the age i.e. group 1 ( $7-17$ years), group $2(18-40$ years) and group 3 (41 - 75 years). Central corneal thickness was also measured by ultrasonic pachymeter. According to their study, Airpuff tonometer readings were significantly higher than both Goldmann applanation tonometer and rebound tonometer measurements in all groups. There was no statistically significant difference between Goldmann applanation tonometer and rebound tonometer measurements in group 1 $(\mathrm{p}=0.248)$, group $2(\mathrm{p}=0.63)$, and group 3 $(\mathrm{p}=0.126)$. In our study, we did not group the subjects on the basis of age. Rather we only included subjects aged between 21 and 39 years with healthy eyes. Moreover, we did not perform pachymetry in our subjects.

Erdogan et $\mathrm{al}^{18}$ conducted a study to compare intraocular pressure (IOP) measurements by noncontact tonometer (NCT), Goldmann applanation tonometry with fluorescein (fGAT), and GAT without fluorescein (nGAT). They also assessed the effect of central corneal thickness (CCT) and keratometric values on IOP. One hundred and eighty eight eyes of 94 healthy subjects were included in the study. Their study showed that there were statistically insignificant differences in IOP values by nGAT and fGAT $(\mathrm{P}>0.05)$, and were correlated positively with NCT readings. IOP readings were independent of CCT and keratometry readings. Whereas in our study we did not 
compare the IOP values obtained by GAT done with and without fluorescein. Our sample size was 25 as compared to 94 in their study.

In another study, Grewal et $\mathrm{al}^{19}$ investigated the correlation among intraocular pressure (IOP) values, in 50 eyes of 50 patients who already had undergone vitreoretinal surgery, obtained by iCare rebound tonometer, Tonopen, and GAT. However, in our study, we only included subjects with healthy eyes with no previous history of trauma or surgery. Mean IOP values obtained by iCare, Tonopen, and Goldmann were $15.9 \pm 8.9,16.9 \pm 6.2$, and $16.0 \pm 7.3 \mathrm{~mm} \mathrm{Hg}$, respectively. They concluded that, post vitreoretinal surgery, there is excellent agreement among IOP values obtained by iCare rebound tonometer, Tonopen, and GAT. They also concluded that iCare overestimated IOP when IOP was $\geq 23 \mathrm{~mm} \mathrm{Hg}$ and underestimated the IOP when IOP was $<10 \mathrm{~mm} \mathrm{Hg}$. We, in our study, did not assess the effect of low or high IOP on iCare tonopen values.

In another study by Takenaka et $\mathrm{al}^{20}$, comparison was done among the IOP values measured by NCT, GAT, iCare tonometer and the Tonopen XL while wearing soft contact lenses (SCLs). IOP was measured in twenty-six healthy subjects, wearing SCLs of -5.00 $\mathrm{D},-0.50 \mathrm{D}$ and +5.00 D, using NCT, GAT, iCare, and the Tono-Pen XL. Using GAT, while wearing +5.00 D lenses, IOP readings were higher than those of the naked eyes. Whereas, when measured by iCare, IOP readings were almost same as measured over SCLs ranging from $-5.00 \mathrm{D}$ to $+5.00 \mathrm{D}$ and were also comparable with values obtained by GAT in the naked eyes. Thus, it was concluded that to measure IOP through SCLs, NCT and iCare were best alternatives. Tonopen XL was not included in our study.

Raina et $\mathrm{al}^{21}$ in their study compared the IOP values obtained by GAT, Tono-Pen and noncontact tonometer in children. They had a sample size of 200 eyes of Indian children (aged $8-18$ years). IOP was measured by using above-mentioned three tonometers. Effect of CCT on IOP was also analyzed. The mean IOP was 14.38 with NCT, 15.63 with Tonopen, and $12.44 \mathrm{~mm} \mathrm{Hg}$ with GAT i.e. lowest with GAT and highest with tonopen. These results contradict the results of our study as mean IOP in our study was $15.84 \pm 2.736 \mathrm{~mm} \mathrm{Hg}$ with Airpuff Tonometer, 14.48 $\pm 2.435 \mathrm{~mm} \mathrm{Hg}$ with iCare Tonopen and $14.74 \pm 2.489$ $\mathrm{mm} \mathrm{Hg}$ with GAT i.e. lowest with iCare tonopen and highest with Airpuff NCT. Therefore, there was some ambiguity regarding the IOP values obtained by different tonometers.

Limitation of our study was that we did not assess the effect of central corneal thickness (CCT) on IOP values obtained by different tonometers. The effect of very low and high IOPs on the measurements was also not investigated with three tonometers.

\section{CONCLUSION}

IOP readings taken by iCare Tonopen and Airpuff Tonometer are comparable to those taken by Goldmann Applanation Tonometer and iCare Tonopen underestimates the IOP when compared with Airpuff Tonometer. Thus iCare rebound tonometry and Airpuff tonometry are reliable alternatives to Goldmann applanation tonometery and both of these can be used to measure IOP in challenging cases.

\section{Ethical Approval}

The study was approved by the Institutional review board/ Ethical review board.

(1-2/20-MIMC/ERB/0018)

\section{Conflict of Interest}

Authors declared no conflict of interest.

\section{REFERENCES}

1. Kim YW, Park KH. Exogenous influences on intraocular pressure, 2019; 103 (9): 1209-1216.

2. De Moraes CG, Liebmann JM, Levin LA. Detection and measurement of clinically meaningful visual field progression in clinical trials for glaucoma. Progress in retinal and eye research, 2017; 56: 107-147.

3. Wang YX, Xu L, Wei WB, Jonas JB. Intraocular pressure and its normal range adjusted for ocular and systemic parameters. The Beijing Eye Study, 2011. 2018; 13 (5): e0196926.

4. Trivli A, Koliarakis I, Terzidou C, Goulielmos GN, Siganos CS, Spandidos DA, et al. Normal-tension glaucoma: Pathogenesis and genetics. Exp Ther Med. 2019; 17 (1): 563-574.

5. Gordon MO, Kass MA. What We Have Learned From the Ocular Hypertension Treatment Study. Am J Ophthalmol. 2018; 189: 226-227

6. Sng CC, Ang M, Barton K. Central corneal thickness in glaucoma. Curr Opin Ophthalmol. 2017; 28 (2): 120126.

7. Foster PJ, Buhrmann R, Quigley HA, Johnson GJ. The definition and classification of glaucoma in prevalence surveys. Br J Ophthalmol. 2002 Feb; 86 (2): 238-42. 
8. Maczynska E, Rzeszewska-Zamiara J, Jimenez Villar A, Wojtkowski M, Kaluzny BJ, Grulkowski I. Air-Puff-Induced Dynamics of Ocular Components Measured with Optical Biometry. Invest Ophthalmol Vis Sci. 2019; 60 (6): 1979-1986.

9. LoVecchio F, Salveson P, Mulrow M, Malashock $\mathbf{H}$. Icare vs. Tono-Pen in the ED. Am J Emer Med. 2016; 34 (3): 670-673.

10. Ragan A, Cote SL, Huang JT. Disinfection of the Goldman applanation tonometer: a systematic review. Canadian J Ophthalmol. 2018; 53 (3): 252-259.

11. Wong B, Parikh D, Rosen L, Gorski M, Angelilli A, Shih C. Comparison of Disposable Goldmann Applanation Tonometer, ICare ic100, and Tonopen XL to Standards of Care Goldmann Nondisposable Applanation Tonometer for Measuring Intraocular Pressure. J Glaucoma, 2018; 27 (12): 1119-1124.

12. Tejwani S, Dinakaran S, Joshi A, Shetty R, Sinha Roy A. A cross-sectional study to compare intraocular pressure measurement by sequential use of Goldman applanation tonometry, dynamic contour tonometry, ocular response analyzer, and Corvis ST. Ind J Ophthalmol. 2015; 63 (11): 815-820.

13. Yildiz A, Yasar T. Comparison of Goldmann applanation, non-contact, dynamic contour and tonopen tonometry measurements in healthy and glaucomatous eyes, and effect of central corneal thickness on the measurement results. Medicinski glasnik: official publication of the Medical Association of Zenica-Doboj Canton, Bosnia and Herzegovina. 2018; 15 (2): 152157.

14. Aceituno Paredes SC, Asturias de León AL, Barnoya Pérez J. Rebound tonometry with resterilised tips versus Goldmann applanation tonometry in children. Archivos de la Sociedad Espanola de Oftalmologia. 2020; 95 (7): 322-326.

15. Pahlitzsch M, Brüner J, Gonnermann J, Maier AB, Torun N, Bertelmann E, et al. Comparison of ICare and IOPen vs. Goldmann applanation tonometry according to international standards 8612 in glaucoma patients. Intern J Ophthalmology, 2016; 9 (11): 16241628.

16. Demirci G, Erdur SK, Tanriverdi C, Gulkilik G, Ozsutçu M. Comparison of rebound tonometry and non-contact airpuff tonometry to Goldmann applanation tonometry. Ther Adv Ophthalmol. 2019; 11: 2515841419835731.
17. Rödter TH, Knippschild S, Baulig C, Krummenauer F. Meta-analysis of the concordance of Icare(®) PRObased rebound and Goldmann applanation tonometry in glaucoma patients. Eur J Ophthalmol. 2020; 30 (2): 245-252.

18. Erdogan H, Akingol Z, Cam O, Sencan S. A comparison of NCT, Goldman application tonometry values with and without fluorescein. Clin Ophthalmol. (Auckland, NZ). 2018; 12: 2183-2188.

19. Grewal DS, Stinnett SS, Folgar FA, Schneider EW, Vajzovic L, Asrani S, et al. A Comparative Study of Rebound Tonometry with Tonopen and Goldmann Applanation Tonometry Following Vitreoretinal Surgery. Am J Ophthalmol. 2016; 161: 22-8.e1-8.

20. Takenaka J, Kunihara E, Rimayanti U, Tanaka J, Kaneko M, Kiuchi Y. Intraocular pressure readings obtained through soft contact lenses using four types of tonometer. Clin Ophthalmol. (Auckland, NZ). 2015; 9: 1875-1881.

21. Raina UK, Rathie N, Gupta A, Gupta SK, Thakar M. Comparison of Goldmann applanation tonometer, Tono-Pen and noncontact tonometer in children. Oman J Ophthalmol. 2016; 9 (1): 22-26.

\section{Authors' Designation and Contribution}

Umair Tariq Mirza; Assistant Professor: Concepts, Design, Data acquisition, Manuscript editing, Manuscript review.

M. Usman Sadiq; Assistant Professor: Concepts, Design, Data acquisition, Data analysis, Statistical analysis, Manuscript review.

M. Irfan Sadiq; Assistant Professor: Concepts, Design, Literature search, Manuscript preparation, Manuscript editing, Manuscript review.

Ali Raza; Professor: Concepts, Design, Manuscript preparation, Manuscript review.

Waseem Ahmed Khan; Professor: Literature search, Manuscript preparation, Manuscript review. 